\title{
FEATURES OF CHANGES IN INDICATORS OF PHYSICAL PREPAREDNESS OF 6-9 GRADE STUDENTS
}

\author{
Sabit Abildabekov, Iosif Andruchsishin, \\ The Kazakh Academy of Sport and Tourism
}

\begin{abstract}
Summary.
In the article, important aspects of improving the process of physical education of students of the secondary schools are examined: the scientific substantiation of an effective system of managing the educational process and the introduction of innovative forms, means and methods of physical culture in pedagogical practice on the basis of objective data on the dynamics of physical development and physical preparedness of students.

The effectiveness of the organization of the physical education system requires the regular information about the level of physical qualification of students, during the period of education in the secondary schools. Now it is well known that an objective assessment of the physical development and physical preparedness of students is conducted on the basis of comparing the results of measurements obtained during the survey with the assessment standards developed taking into account the age and gender characteristics of middle and senior school age. Lyakh V.I. 2005.

In this way, for an objective analysis of monitoring data and making informed decisions on the correction of program material for the physical education of schoolchildren, information is needed on the structure and significance of the main factors determining the structure of the motor skills of students of different ages and sex. The actual direction of optimization of pedagogical control in the physical education of schoolchildren is the development of an integral formalized assessment of the physical readiness of students in general education institutions, taking into account the individual structure of the motor skills of schoolchildren. Levushkin S. P. 2006, Matveev AP, Nazarkina N. I. 2005.

The results of our research were mixed, especially in changing of individual indicators of physical fitness. There was confirmation of the fact that physical education lessons for boys are ineffective in the 8th-9th grades on the development of hand strength, flexibility and strength of the abdominal press; in girls, a decrease in the effectiveness of lessons is noted to the 9 th grade. This is due to the deterioration of speed and power capabilities, the development of hand strength and abdominal pressure.
\end{abstract}

Keywords: Physical education, new programs and technologies, school students, physical qualities.

Introduction. The problem of improving the quality of instruction in physical education is socially determined and dictated by the demands of the time. In many respects it is connected with aspects of practical statement of the school subject "Physical Culture". First of all, it is about fulfilling the requirements of the normative parts of the curricula. In accordance with the contents of these programs, the school should ensure the full-fledged mastering of the teaching materials by the students in all five Olympic sports disciplines. Only in this case it is possible to successfully solve the problems of comprehensive physical preparation of children in different periods of studying.

The aim. Study of the impact of teaching and upbringing on the physical preparedness of students in 6-9 grades for physical education.

The task. To study the features of changing the indicators of physical readiness of students of 6-9 grades in the subject "Physical Culture" in connection with the implementation of the content of new curricula.

The object of the study. Students of 6-9 grades of the secondary school № 34, 128, 141 in Almaty.

Physical fitness was determined on the basis of testing such physical qualities as: high-speed strength (jump in length from the location shown in Figure 1A); dexterity (shuttle run for a time, depicted in Figure 1B); force of the abdominal press (the exercise is shown in Figure 1B); the relative strength of the arms (flexion and extension of the arms in the support lying); Flexibility (inclination of the trunk to the legs from the saddle on the floor, depicted in Figure 2).

Results of the research. Testing boys 6-9 grades showed the following (Table 1).

\section{A long jump from the place}

In the 6th grade this indicator is higher than in the 7 th by $12.2 \%$ and lower than in the 8 th and 9 th grades by 3.6 and $10.5 \%$, respectively.

The indicators of the 7 th grade were lower than those of the 8th and 9th grades by 17.9 and $25.8 \%$, respectively; the results in grade 8 were worse than in the 9 th by $6.7 \%$. 
2. Exercise "push-up" in the supine position.

The results of the boys of the 6th grade ranged from $20.6 \pm 0.72$ push-ups per minute. At the 7 th grade level, this indicator increased by 18.9

at the 8th grade level - at 85.4 and at the 9th level at $59.7 \%$. In the 7 th class, the number of "push-ups" was less than in the 8th by 55.9 and less than in the 9th - by $34.3 \%$.

When comparing the data of the 8th and 9th grades, it was revealed: this power factor in 8 -graders is higher than in 9 -graders by almost $14 \%$.

1. Exercise "flexibility" sitting on the floor. Flexibility indicators for boys of the 6th grade reached the limits of $6.5 \pm 0.11 \mathrm{~cm}$. This index improved significantly in the 7 th grade, and in 8 and 9th grades differed little from the achievements of 6-graders. The boys of the 7th grade were more flexible than the boys of the 8th, because Reliable differences in the results were almost $33.3 \%$. But in the same 7-graders the results were higher than in the 9-graders by almost 53\%; in the 9th grade, compared to with the 8th, flexibility deteriorated, although this deterio- ration in the digital value is not significant.

2. Shuttle running. The result of the shuttle race in the 6th grade was $8.8 \pm 0.07$ seconds. This index slightly fluctuated in the 7 th and 8 th grades, but significantly improved only in the 9th grade, reaching a level of $6.7 \pm 0.12$ seconds, i.e. almost by $24 \%$. The results of the 7 th and 8th grades differed little, and the 7th and 9th had a difference of more than $20 \%$ in favor of the 9th grade; in addition, the speed of the shuttle run in the 9th grade was higher than in the 8 th by $23 \%$.

5. Exercise "abdominal press" lying on his back, bending his knees. In the performance of this test, the results of grades 6 and 7 differed little from each other and averaged 31-32.7 trunk elevations per minute. But at the level of 8th grade, this indicator naturally improved by 42.3 , and at the 9 th level - by $39 \%$.

Comparative data of 7 th, 8th and 9th grades showed: the results of boys of the 7th grade are lower than the 8th and 9th grades by 33.9 and $31.8 \%$, respectively. The differences in the results of the 8th and 9th grades turned out to be unreliable and ranged from 43.1 to 43.8 rises per minute.

Table 1 - Results of testing the physical fitness of boys (6-9grades)

\begin{tabular}{|c|c|c|c|c|c|c|}
\hline \multirow[t]{2}{*}{ Index } & \multicolumn{2}{|c|}{6 grade } & \multicolumn{2}{|c|}{7 grade } & \multirow[b]{2}{*}{$\mathrm{t}$} & \multirow[b]{2}{*}{$\mathrm{P}$} \\
\hline & $\bar{x}$ & $S$ & $\bar{x}$ & $S$ & & \\
\hline long jump from the place, $\mathrm{cm}$ & 181,0 & 11,9 & 159,0 & 16,52 & 7,3 & $<0,001$ \\
\hline exercise «push-up» in the support lying for $1 \mathrm{~min}$ & 20,6 & 4,19 & 38,2 & 7,46 & 2,62 & $<0,05$ \\
\hline exercise «flexibility», cm & 6,5 & 0,64 & 11,9 & 6,52 & 6,48 & $<0,001$ \\
\hline shutle run, sec & 8,8 & 0,40 & 8,44 & 11,1 & 0,24 & $>0,05$ \\
\hline exercise on the «abdominal press» for $1 \mathrm{~min}$ & 31,0 & 11,9 & 32,7 & 7,6 & 5,1 & $<0,001$ \\
\hline \multirow[t]{2}{*}{ Index } & \multicolumn{2}{|c|}{6 grade } & \multicolumn{2}{|c|}{8 grade } & \multirow[t]{2}{*}{$\mathrm{t}$} & \multirow[t]{2}{*}{$\mathrm{P}$} \\
\hline & $\bar{x}$ & $S$ & $\bar{x}$ & $S$ & & \\
\hline long jump from the place, $\mathrm{cm}$ & 181,0 & 11,9 & 187,5 & 1,78 & 7,3 & $<0,001$ \\
\hline exercise «push-up» in the support lying for $1 \mathrm{~min}$ & 20,6 & 4,19 & 24,5 & 9,78 & 3,1 & $<0,05$ \\
\hline exercise «flexibility», cm & 6,5 & 0,64 & 8,0 & 3,24 & 1,36 & $>0,05$ \\
\hline shutle run, sec & 8,8 & 0,40 & 8,7 & 0,64 & 0,42 & $>0,05$ \\
\hline exercise on the «abdominal press» for $1 \mathrm{~min}$ & 31,0 & 11,9 & 43,8 & 7,46 & 5,1 & $<0,001$ \\
\hline \multirow[t]{2}{*}{ Index } & \multicolumn{2}{|c|}{6 grade } & \multicolumn{2}{|c|}{9 grade } & \multirow[t]{2}{*}{$\mathrm{t}$} & \multirow[t]{2}{*}{$\mathrm{P}$} \\
\hline & $\bar{x}$ & $S$ & $\bar{x}$ & $S$ & & \\
\hline long jump from the place, $\mathrm{cm}$ & 181,0 & 11,9 & 200,2 & 17,5 & 4,82 & $<0,001$ \\
\hline exercise «push-up» in the support lying for $1 \mathrm{~min}$ & 20,6 & 4,19 & 32,9 & 8,75 & 6,69 & $<0,001$ \\
\hline exercise «flexibility», cm & 6,5 & 0,64 & 5,37 & 6,25 & 0,93 & $>0,05$ \\
\hline shutle run, sec & 8,8 & 0,40 & 6,7 & 0,63 & 15,4 & $<0,001$ \\
\hline exercise on the «abdominal press» for $1 \mathrm{~min}$ & 31,0 & 11,9 & 43,11 & 5,75 & 10,1 & $<0,001$ \\
\hline \multirow[t]{2}{*}{ Index } & \multicolumn{2}{|c|}{7 grade } & \multicolumn{2}{|c|}{8 grade } & \multirow[t]{2}{*}{$\mathrm{t}$} & \multirow[t]{2}{*}{$\mathrm{P}$} \\
\hline & $\bar{x}$ & $S$ & $\bar{x}$ & $S$ & & \\
\hline long jump from the place, $\mathrm{cm}$ & 159,0 & 16,52 & 187,5 & 1,78 & 12,46 & $<0,001$ \\
\hline exercise «push-up» in the support lying for $1 \mathrm{~min}$ & 38,2 & 7,46 & 24,5 & 9,78 & 4,62 & $<0,001$ \\
\hline exercise «flexibility», $\mathrm{cm}$ & 11,9 & 6,52 & 8,0 & 3,24 & 2,81 & $<0,05$ \\
\hline shutle run, sec & 8,44 & 11,1 & 8,7 & 0,64 & 0,17 & $>0,05$ \\
\hline exercise on the «abdominal press» for $1 \mathrm{~min}$ & 32,7 & 7,6 & 43,8 & 7,46 & 4,14 & $<0,01$ \\
\hline
\end{tabular}




\begin{tabular}{|l|c|c|c|c|c|c|}
\hline \multirow{2}{*}{ Index } & \multicolumn{2}{|c|}{7 grade } & \multicolumn{2}{c|}{ 9 grade } & \multirow{2}{*}{ P } \\
\cline { 2 - 6 } & $\bar{x}$ & $S$ & $\bar{x}$ & & & \\
\hline long jump from the place, cm & 159,0 & 16,52 & 200,2 & 17,5 & 10,17 & $<0,001$ \\
\hline exercise «push-up» in the support lying for 1 min & 38,2 & 7,46 & 32,9 & 8,75 & 3,93 & $<0,05$ \\
\hline exercise «flexibility», cm & 11,9 & 6,52 & 5,37 & 6,25 & 4,41 & $<0,01$ \\
\hline shutle run, sec & 8,44 & 11,1 & 6,7 & 0,63 & 1,2 & $>0,05$ \\
\hline $\begin{array}{l}\text { exercise on the «abdominal press» } \\
\text { for 1 min }\end{array}$ & 32,7 & 7,6 & 43,11 & 5,75 & 6,97 & $<0,001$ \\
\hline
\end{tabular}

\begin{tabular}{|l|c|c|c|c|c|c|}
\hline \multirow{2}{*}{ Index } & \multicolumn{2}{|c|}{8 grade } & \multicolumn{2}{c|}{ 9 grade } & \multirow{2}{*}{ P } & \\
\cline { 2 - 6 } & $\bar{x}$ & & $\bar{x}$ & & & \\
\hline long jump from the place, cm & 187,5 & 1,78 & 200,2 & 17,5 & 3,62 & $<0,05$ \\
\hline exercise «push-up» in the support lying for 1 min & 24,5 & 9,78 & 32,9 & 8,75 & 2,62 & $<0,05$ \\
\hline exercise «flexibility», cm & 8,0 & 3,24 & 5,37 & 6,25 & 1,63 & $>0,05$ \\
\hline shutle run, sec & 8,7 & 0,64 & 6,7 & 0,63 & 8,1 & $<0,001$ \\
\hline $\begin{array}{l}\text { exercise on the «abdominal press» } \\
\text { for 1 min }\end{array}$ & 43,8 & 7,46 & 43,11 & 5,75 & 0,25 & $>0,05$ \\
\hline
\end{tabular}

The results of testing girls more clearly reflected the age features in the change in physical fitness indicators (Table 2).

1. Jump long from the place. The length of this jump was $161.0 \pm 2.04 \mathrm{~cm}$. of girls of the 6th grade, in the 7 th grade, this index significantly decreased by 8.3 , in the 8 th - by 13.9 , and in the 9 th class - by $4.8 \%$.

The results of the 7 th and 8 th grades differed little. The differences between the indices of the 8th and 9th grades turned out to be significant; the jump in the 9th grade was $153.25 \pm 3.14 \mathrm{~cm}$, which is $10.6 \%$ more than in the 8 th.

2. Exercise "push-up" in the supine position. According to the data of the 6th grade, the number of "push-ups" here fluctuated in the range of 13.2 \pm 1.9 times. Further, at the 7 th, 8 th and 9 th grade levels, this result improved, respectively: by $84.6 \%$; by 55.3 and $19.8 \%$.

When comparing the results of classes 7 and 8 , the differences were insignificant; at the same time, the results of the 9th grade were lower than in the 7th - by more than $35 \%$, and lower than in the 8 th - by almost $23 \%$.

3. Exercise "flexibility". Flexibility in the torso was more than satisfactory of girls of the 6th and 7th grades, flexibility in the torso was more than satisfactory and was expressed in figures of $12.5-12.02 \mathrm{~cm}$.

In the 8th grade, these indicators worsened by $42.9 \%$, and in the 9 th - improved by $43.2 \%$; on a par with that the results of the 7 th grade were high- er than in the 8th (40.6\%) and lower than the 9th (43\%) grades. In the 9th grade, compared with the 8 th grade, the state of flexibility improved more than 2.4 times.

4. Shuttle run. According to the results of the shuttle race, the indicators of the 6th and 7th grades were almost equal and varied within 9.4-9.23 seconds. In the 8th grade, these indicators worsened by $9.5 \%$, and in the 9 th - they improved by $11.4 \%$.

When comparing the data of the 7 th and 8 th grades, the deterioration of the result in the 8th class was revealed by $11.5 \%$, and when comparing the data of the 7th and 9th grades, an insignificant improvement was observed in the 9th grade. Differences in running speed in the 8th and 9th grades proved to be reliable in favor of the 9th class, where the result was higher than in the 8 th more than $19 \%$.

5. Exercise "abdominal press", laying on his back, bending his knees, this figure was an average of 19.0 \pm 0.49 rises in 1 minute for girls in the 6th grade. In the 7 th, 8 th and 9 th grades, this indicator naturally improved accordingly: by 60,57 and $30.6 \%$; between the results of the 7th and 8th classes there was no reliable difference.

Indicators of the 9th grade were higher than in the 7 th by $18.6 \%$ and differed little from the indicators of the 8 th grade.

Thus, based on the results of a study of boys, speedstrength training consistently improves from 6th to 9th grade, taking into account a significant deterioration in the 7th grade; strength endurance of 
the muscles of the hands ("push-up") is consistently flexibility deteriorates at the 9th grade level, reachworsening at the levels of 8 and 9th grades, reach- ing $5.37 \mathrm{~cm}$, the value of the 6th grade;

ing 38.2-32.9 "push-ups" per minute; The index of

Table 2 - Results of testing the physical fitness of girls of 6-9 grades

\begin{tabular}{|c|c|c|c|c|c|c|}
\hline \multirow[t]{2}{*}{ Index } & \multicolumn{2}{|c|}{6 grade } & \multicolumn{2}{|c|}{7 grade } & \multirow[t]{2}{*}{$\mathrm{t}$} & \multirow[t]{2}{*}{$\mathrm{P}$} \\
\hline & $\bar{x}$ & $S$ & $\bar{x}$ & $S$ & & \\
\hline long jump from the place, $\mathrm{cm}$ & 161,0 & 11,8 & 147,7 & 16,35 & 3,94 & $<0,05$ \\
\hline exercise «push-up» in the support lying for $1 \mathrm{~min}$ & 13,2 & 11,1 & 24,37 & 9,34 & 4,78 & $<0,01$ \\
\hline exercise «flexibility», cm & 12,5 & 5,24 & 12,02 & 5,84 & 0,48 & $>0,05$ \\
\hline shutle run, sec & 9,4 & 0,57 & 9,4 & 0,57 & 0,63 & $>0,05$ \\
\hline exercise on the «abdominal press»for $1 \mathrm{~min}$ & 19,0 & 2,85 & 30,47 & 10,0 & 6,63 & $<0,001$ \\
\hline \multirow[t]{2}{*}{ Index } & \multicolumn{2}{|c|}{6 grade } & \multicolumn{2}{|c|}{8 grade } & \multirow[t]{2}{*}{$\mathrm{t}$} & \multirow[t]{2}{*}{$\mathrm{P}$} \\
\hline & $\bar{x}$ & $S$ & $\bar{x}$ & $S$ & & \\
\hline long jump from the place, $\mathrm{cm}$ & 161,0 & 11,8 & 138,6 & 12,96 & 8,5 & $<0,001$ \\
\hline exercise «push-up» in the support lying for $1 \mathrm{~min}$ & 13,2 & 11,1 & 20,5 & 5,55 & 2,96 & $<0,05$ \\
\hline exercise «flexibility», $\mathrm{cm}$ & 12,5 & 5,24 & 7,14 & 1,85 & 4,55 & $<0,01$ \\
\hline shutle run, sec & 9,4 & 0,57 & 10,2 & 0,37 & 4,94 & $<0,01$ \\
\hline exercise on the «abdominal press»for $1 \mathrm{~min}$ & 19,0 & 2,85 & 29,86 & 5,56 & 4,68 & $<0,01$ \\
\hline
\end{tabular}

\begin{tabular}{|c|c|c|c|c|c|c|}
\hline \multirow[t]{2}{*}{ Index } & \multicolumn{2}{|c|}{6 grade } & \multicolumn{2}{|c|}{9 grade } & \multirow[t]{2}{*}{$\mathrm{t}$} & \multirow[t]{2}{*}{$\mathrm{P}$} \\
\hline & $\bar{x}$ & $S$ & $\bar{x}$ & $S$ & & \\
\hline long jump from the place, $\mathrm{cm}$ & 161,0 & 11,8 & 153,2 & 11,33 & 2,07 & $<0,05$ \\
\hline exercise «push-up» in the support lying for $1 \mathrm{~min}$ & 13,2 & 11,1 & 15,81 & 4,53 & 1,15 & $>0,05$ \\
\hline exercise «flexibility», cm & 12,5 & 5,24 & 17,19 & 5,67 & 2,97 & $<0,05$ \\
\hline shutle run, sec & 9,4 & 0,57 & 8,33 & 1,39 & 2,72 & $<0,05$ \\
\hline exercise on the «abdominal press»for $1 \mathrm{~min}$ & 19,0 & 2,85 & 24,81 & 7,08 & 2,86 & $<0,05$ \\
\hline \multirow[t]{2}{*}{ Index } & \multicolumn{2}{|c|}{7 grade } & \multicolumn{2}{|c|}{8 grade } & $\mathrm{t}$ & $\mathrm{P}$ \\
\hline & $\bar{x}$ & $S$ & $\bar{x}$ & $S$ & & \\
\hline long jump from the place, $\mathrm{cm}$ & 147,7 & 16,35 & 138,6 & 12,96 & 1,53 & $>0,05$ \\
\hline exercise «push-up» in the support lying for $1 \mathrm{~min}$ & 24,37 & 9,34 & 20,5 & 5,55 & 1,35 & $>0,05$ \\
\hline exercise «flexibility», $\mathrm{cm}$ & 12,06 & 5,84 & 7,14 & 1,85 & 3,98 & $<0,05$ \\
\hline shutle run, sec & 9,4 & 0,57 & 10,29 & 0,37 & 3,64 & $<0,05$ \\
\hline exercise on the «abdominal press»for $1 \mathrm{~min}$ & 30,47 & 10,0 & 29,86 & 5,56 & 0,61 & $>0,05$ \\
\hline
\end{tabular}

\begin{tabular}{|c|c|c|c|c|c|c|}
\hline \multirow[t]{2}{*}{ Index } & \multicolumn{2}{|c|}{7 grade } & \multicolumn{2}{|c|}{9 grade } & \multirow[t]{2}{*}{$\mathrm{t}$} & \multirow[t]{2}{*}{$\mathrm{P}$} \\
\hline & $\bar{x}$ & $S$ & $\bar{x}$ & $S$ & & \\
\hline long jump from the place, $\mathrm{cm}$ & 147,7 & 16,35 & 153,2 & 11,33 & 1,35 & $>0,05$ \\
\hline exercise «push-up» in the support lying for $1 \mathrm{~min}$ & 24,37 & 9,34 & 15,81 & 4,53 & 4,3 & $<0,01$ \\
\hline exercise «flexibility», $\mathrm{cm}$ & 12,02 & 5,84 & 17,19 & 5,67 & 2,8 & $<0,05$ \\
\hline shutle run, sec & 9,4 & 0,57 & 8,33 & 1,39 & 1,98 & $>0,05$ \\
\hline exercise on the «abdominal press»for $1 \mathrm{~min}$ & 30,4 & 10,0 & 24,81 & 7,08 & 2,20 & $<0,05$ \\
\hline \multirow[t]{2}{*}{ Index } & \multicolumn{2}{|c|}{8 grade } & \multicolumn{2}{|c|}{9 grade } & \multirow[t]{2}{*}{$\mathrm{t}$} & \multirow[t]{2}{*}{$\mathrm{P}$} \\
\hline & $\bar{x}$ & $S$ & $\bar{x}$ & $S$ & & \\
\hline long jump from the place, $\mathrm{cm}$ & 138,6 & 12,96 & 153,2 & 11,33 & 2,38 & $<0,05$ \\
\hline exercise «push-up» in the support lying for $1 \mathrm{~min}$ & 20,5 & 5,55 & 15,81 & 4,53 & 1,81 & $>0,05$ \\
\hline exercise «flexibility», cm & 7,14 & 1,85 & 17,19 & 5,67 & 5,7 & $<0,001$ \\
\hline shutle run, sec & 10,29 & 0,37 & 8,33 & 1,39 & 4,8 & $<0,01$ \\
\hline exercise on the «abdominal press» for $1 \mathrm{~min}$ & 29,86 & 5,56 & 24,81 & 7,08 & 1,68 & $>0,05$ \\
\hline
\end{tabular}

The speed of the shuttle run only in the 9th class $43-43.8$ rise in minutes, which is 39 and $42 \%$ more reaches $6.7 \pm 0.12$ seconds, and in the 6th, 7 th and than in the 6th and 7th grades.

8th grades it fluctuates within $8.4-8.8$ seconds; en-

durance of abdominal muscles is very high at the According to the results of the study of girls, the 8th and 9th grade levels and reaches an average of speed-strength training index varies from 6th to 
9th grade unevenly and within the limits of a reliable level gradually decreases from $161 \mathrm{~cm}$ to 153 $\mathrm{cm}$; strength endurance of the muscles of the hands was the highest at the levels of 7-8 classes; to the 9 th class, this endurance is reduced to the level of the 6th grade; the indicator of girls' flexibility varies little from class to class and remains at the level of the middle-aged up to the 9th grade, complying with objective measures of $12-17 \mathrm{~cm}$; The speed of the shuttle run increases most noticeably in the 9th grade, making 8.3 seconds; endurance of the muscles of the abdominal press is best manifested in the 7 th and 8th grades, reaching 29-30 rises in $1 \mathrm{~min}$; in the 9th grade the results are closer to the results of the 6th grade.

The conclusion. It is known from literary sources: during the whole school period, the distinct development of physical qualities and the intensification of sensitive manifestations are noted on average by $20.5 \%$ in relation to the perception of exercises aimed at the education of certain motor qualities. Mustayev V.L. 2003, Polyakov M.I.2002., Rudnitsky V.F, 2002, Teleugaliev U.G. 2001.

The results of our research in this sense have been mixed, especially in changing individual indicators of physical fitness. It is confirmed that the physical culture lessons of boys are not very effective in the 8th-9th grades on the development of hand strength, flexibility and strength of the abdominal press; in girls, a decrease in the effectiveness of lessons is observed towards the 9th grade, which is associated with a deterioration in the speed-strength indicators, the development of hand strength and the abdominal pressure.

\section{Literature:}

Lyakh V.I. Teaching and learning of motor actions // Physical culture in school.- 2005.- No. 1 - C. 18-24.

Levushkin S.P. Sensitive periods in the development of the physical qualities of schoolchildren of 7-17 years old with different types of physique // Physical culture: education, education, and training.- 2006.- № 6 - C. 2-4.

Matveev AP, Nazarkina N.I. What should be the textbook on physical culture / / Physical culture in school.2005.- No. 4.- P. 4-6.

Mustayev V.L. By increment. Assessment of physical preparedness of schoolchildren / / Physical culture in school.- 2003.- № 2.- P. 26-28.

Polyakov M.I. On the development of physical qualities / / Physical culture in school.- 2002.- No. 1.- P. 18-20.

Rudnitsky V.F. Criteria of academic achievement // Physical culture in school.- 2002.- № 5.- P. 56-58.

Teleugaliev U.G. Training in physical exercises and optimizing the content of motor activity (monograph).- Almaty: "Print", 2001.- 260 p. 